Review Article

\title{
Intestinal Microbiota and Liver Diseases: Insights into Therapeutic Use of Traditional Chinese Medicine
}

\author{
Tingshuai Wang $\mathbb{D},{ }^{1,2}$ Shaodong Huang $\left(\mathbb{D},{ }^{3}\right.$ Cong Wu $\mathbb{D},{ }^{1}$ Na Wang $\mathbb{D},{ }^{1}$ \\ Rongzhen Zhang $\mathbb{D},{ }^{1}$ Minggang Wang $\mathbb{D}^{4},{ }^{4}$ and Dewen Mao $\mathbb{i D}^{1}$ \\ ${ }^{1}$ Department of Hepatology, The First Affiliated Hospital of Guangxi University of Chinese Medicine, Nanning 530023, Guangxi, \\ China \\ ${ }^{2}$ School of Chinese Medicine, Hunan University of Traditional Chinese Medicine, Changsha 410208, Hunan, China \\ ${ }^{3}$ Department of Gastroenterology, Guangxi Orthopedics and Traumatology Hospital, Nanning 530023, Guangxi, China \\ ${ }^{4}$ Department of Scientific Research, The First Affiliated Hospital of Guangxi University of Chinese Medicine, Nanning 530023, \\ Guangxi, China
}

Correspondence should be addressed to Minggang Wang; wmgyx2012@163.com and Dewen Mao; mdwboshi2005@163.com

Received 27 October 2020; Revised 1 March 2021; Accepted 10 April 2021; Published 23 April 2021

Academic Editor: Célia Cabral

Copyright (c) 2021 Tingshuai Wang et al. This is an open access article distributed under the Creative Commons Attribution License, which permits unrestricted use, distribution, and reproduction in any medium, provided the original work is properly cited.

\begin{abstract}
Liver disease is a leading cause of global morbidity and mortality, for which inflammation, alcohol use, lipid metabolic disorders, disturbance to bile acid metabolism, and endotoxins are common risk factors. Traditional Chinese Medicine (TCM) with its "holistic approach" is widely used throughout the world as a complementary, alternative therapy, due to its clinical efficacy and reduced side effects compared with conventional medicines. However, due to a lack of reliable scientific evidence, the role of TCM in the prevention and treatment of liver disease remains unclear. Over recent years, with the rapid development of highthroughput sequencing, $16 \mathrm{~S}$ rRNA detection, and bioinformatics methodology, it has been gradually recognized that the regulation of intestinal microbiota by TCM can play a substantial role in the treatment of liver disease. To better understand how TCM regulates the intestinal microbiota and suppresses liver disease, we have reviewed and analyzed the results of existing studies and summarized the relationship and risk factors between intestinal microbiota and liver disease. The present review summarizes the related mechanisms by which TCM affects the composition and metabolites of the intestinal microbiome.
\end{abstract}

\section{Introduction}

Diseases of the liver, including viral hepatitis, liver cirrhosis, nonalcoholic fatty liver disease (NAFLD), liver failure, and liver cancer, affect millions of individuals in China, now representing one of the leading causes of morbidity and mortality [1]. While viruses, inflammation, lipid metabolism, immune response, and bile acid are common pathological mechanisms and risk factors affecting the development of liver disease, none of these factors can fully explain its occurrence and progression.

In recent years, the influence of intestinal microbiota on liver disease has become increasingly apparent $[2,3]$. There are approximately $10^{14}$ microorganisms in the human gastrointestinal (GI) tract, which play an important role in maintaining human health [4]. Changes in the abundance, composition, and fundamental function of the gut microbiome can induce or exacerbate liver disease [5-9]. Studies of the influence of GI flora on the pathogenesis of liver disease are critical in this respect, and it may become a novel therapeutic target for the prevention and treatment of liver disease.

Traditional Chinese Medicine (TCM) is an important component of China's ancient and splendid culture and has been in popular use for thousands of years $[10,11]$. As oral administration is among the most common methods of administration of TCM, drugs pass along the intestinal tract and establish a relationship with the intestinal flora [12]. 
Increasing evidence has shown that monomers or compounds of TCMs can regulate the composition of intestinal flora and its metabolites via the "liver-gut" axis, thereby playing an important role in immune regulation, reversing liver fibrosis, promoting liver regeneration, and reducing inflammatory injury through other modalities, delaying or even reversing the progression of liver disease [13-15]. Detailed research focusing on the relationship between TCM and liver disease is required to elucidate the therapeutic mechanism(s) of TCMs.

In the present review, we first summarize the interactions between intestinal flora and liver disease. We will then review the relationship between intestinal flora and risk factors for liver disease, including inflammation, alcohol use, lipid metabolism, and bile acid metabolism. Lastly, we will summarize the regulatory effect of TCM on intestinal microbial composition and metabolites and illustrate the related mechanisms by which the influence of TCMs on intestinal microbiota prevents and treats liver disease.

\section{Interaction between Intestinal Microbiota and Liver Disease}

The liver-gut axis is an important link between gut microbiota and liver disease. Since $70 \%$ of the liver's blood supply comes from the gut via the portal vein, it is constantly at risk of exposure to gut bacterial components such as DNA, metabolites, toxins, lipopolysaccharide (LPS), and peptidoglycans $[16,17]$. Intestinal flora is also an important element of the intestinal barrier system, playing a critical role in delaying the release of toxic substances into the bloodstream and maintaining intestinal homeostasis. In addition, intestinal flora participates in the bioconversion of bile acid and regulates hepatointestinal circulation. Trimethylamine (TMA), a metabolite derived from intestinal flora, can be converted into trimethylamine oxide (TMAO) in the liver, which not only damages hepatocytes, but also results in choline deficiency and hepatic steatosis, increasing the risk of liver cancer. Intestinal microbiota may, therefore, be critical in maintaining liver-gut axis homeostasis that limits the pathogenesis of liver disease.

2.1. Viral Hepatitis. Studies have found that changes in diversity and structure in the gut microbiome play important roles in inducing and promoting the development of viral hepatitis $[18,19]$. Two recent studies have revealed the relationship of $\mathrm{HBV}, \mathrm{HCV}$ with the intestinal microbiota, in addition to its link with $\mathrm{CHB}$ and $\mathrm{CHC}[20,21]$. It has been found that, in $\mathrm{HBV}$-induced chronic liver disease (HBVCLD) and HCV-induced chronic liver disease (HCVCLD), bacterial flora diversity had declined, with a notable decrease in Bifidobacterium and Clostridiaceae, and increased Enterobacteriaceae family bacteria (such as Streptococcus and Lactobacillus). Bifidobacteria are important probiotics that reduce endotoxin levels in the plasma and intestine, maintain intestinal microbial homeostasis, produce antibacterial factors, improve intestinal barrier function, and regulate systemic immunity [22, 23].
Clostridiaceae are an additional group of probiotics that represents the main commensal and butyrate-producing group of bacteria. Enterobacteriaceae are nondominant flora, the excessive growth of which may release large quantities of endotoxin into the intestinal tract, inhibiting protein synthesis in intestinal epithelial cells that leads to intestinal barrier injury, bacterial translocation, and floral imbalance [24]. In addition, changes in the composition of gut microbiota are also associated with the production of bile acid, the reduction of which can lead to the excessive growth of pathogenic and proinflammatory bacterial species such as Enterobacteriaceae and Porphyromonadaceae [25].

Hepatic cells are destroyed by HBV or HCV infection, negatively impacting the homeostasis of the liver-gut axis and leading to other dangerous consequences (such as inflammation or immune injury). Thus, determining the composition of the microbiome provides a new tool for establishing the relationship between diseases caused by viral infection and inflammation, immunization, and bile acid metabolism.

2.2. Nonalcoholic Fatty Liver Disease (NAFLD). Obesity and a high-fat diet (HFD) are important risk factors for NAFLD and are associated with qualitative and quantitative changes in the intestinal flora. In a prospective, cross-sectional study that compared the gut microbiome in patients with NAFLD with healthy subjects, $20 \%$ more Bacteroidetes and $24 \%$ fewer Firmicutes were observed in the NAFLD group. The reduction in Firmicutes included 8 genera of SCFA-producing bacteria, including $7 \alpha$-dehydroxylating Ruminococcaceae [26]. It has been demonstrated that SCFAs reduce the quantity of stored lipid, thus altering hepatic metabolic processes. SCFA levels (including acetic acid, propionic acid, butyrate, propionate, and butyrate) in NALFD mice were significantly higher following their treatment with Silybin (a hepatoprotective agent), possibly related to changes in the intestinal flora, especially the significant decrease in Firmicutes and Bacteroides [27]. Lipid metabolism can affect endogenous ethanol (EnEth) fermentation, a process in which certain gut bacteria (HiAlc K. pneumoniae) are involved, promoting the development of NAFLD. Chen et al. found that serum aspartate transaminase (AST), alanine transaminase (ALT), triglycerides (TG), and malondialdehyde (MDA) levels increased when the alcohol production capacity of the high alcohol-producing (HiAlc) Klebsiella pneumonia strain W14 increased, with lipid accumulation severely damaging liver tissue, as observed in histology [28]. In addition, TMAO affects bile acid metabolism and exacerbates hepatic steatosis. It was observed that TMAO levels in patients with NAFLD positively correlated with BA levels in serum and BA synthesis. This suggests that TMAO leads to increased BA synthesis and regulates BA composition toward FXR antagonistic activity, thereby inhibiting the activation of FXR in the liver, consequently improving lipogenesis [29].

NAFLD is an extremely complex disease that arises from interactions between the gut microbiota, diet, genes, and environment. In addition to directly inducing NAFLD, the 
gut microbiota can drive the severity of NAFLD and promote nonalcoholic steatohepatitis (NASH), liver fibrosis, liver cirrhosis, and even liver cancer. The prevention and treatment of NAFLD via regulation of the microbiome are a promising area of research for the identification of new therapeutic targets.

2.3. Liver Cirrhosis. Intestinal changes frequently occur in cirrhotic patients that can include intestinal bacterial overgrowth, bacterial translocation (BT), disruption to the intestinal barrier, and increased levels of endotoxins [30, 31]. A prospective study found that microbial diversity decreased in cirrhotic patients, and it is even lower in those with decompensated cirrhosis. As the disease progresses, a progressively increased abundance of Enterococcaceae and Enterobacteriaceae has been observed to be positively correlated with Model for end-stage liver disease (MELD) scores and endotoxin levels $[32,33]$. SCFAs are an important source of energy for intestinal epithelial cells and can enhance the intestinal barrier by promoting cell differentiation, production of mucin and antimicrobial peptides, and upregulation of tight junction proteins [34]. SCFAs also have an anti-inflammatory effect by inhibition of NF- $\kappa \mathrm{B}$ activity. Lactobacillus and Eubacterium, the principal SCFA-producing genera, are significantly reduced in cirrhosis patients [35]. Bile acids play a pleiotropic role in the maintenance of intestinal barrier homeostasis. Animal models of bile acid deficiency have allowed the observation of the effects of intestinal bacterial overgrowth, inflammation, increased permeability, and BT on mesenteric lymph nodes (MLN) [36].

Cirrhosis is preceded by fibrosis and eventually develops into liver cancer. Fundamental and clinical research into cirrhosis has also examined the microbiome [37-39], aiming to identify key microorganisms and their metabolites, and examining the effects on BT and intestinal permeability. By elucidating the relationship between the microbiome and liver cirrhosis, the eventual aim is to utilize this knowledge to reverse or inhibit cirrhosis and prevent hepatocellular carcinoma (HCC).

2.4. Liver Failure. Qualitative and quantitative changes to the microbiome, including dysbiosis and bacterial overgrowth, are closely linked to liver failure, due to hepatocyte apoptosis, inflammatory reactions, and endotoxemia, which exacerbate liver damage. The imbalance in intestinal microflora accelerates the progression of liver failure. Chen et al. [40] found that ACLF patients had a lower abundance of Bacteroidaceae, Ruminococcaceae, and Lachnospiraceae and a higher abundance of Pasteurellaceae, Streptococcaceae, and Enterococcaceae. Through correlation-network analysis, it was found that TNF- $\alpha$ was negatively correlated with Proteobacteria, Burkholderiales, and Bacteroidetes and that the relative abundance of Oscillibacter spp., Butyricimonas $s p p$., and $B$. virosa was positively associated with levels of IL$1 \beta$, TNF- $\alpha$, and chemokines such as GM-CSF, CXCL1, MIP$1 \alpha$, CCL5, and MCP-1. In addition to the inflammatory response, gut microbiota also affects the progression of liver failure. One study found that, in ACLF patients, the number of immunomodulatory monocytes and MERTK-expressing macrophages increased, inhibiting the innate immune response to microorganisms [41].

Liver failure is an important clinical challenge as a highly prevalent, life-threatening disease with few current therapeutic options available. Although the pathophysiology of liver failure still requires elucidation, the gut microbiota and associated metabolites, in addition to BT, are thought to be all major contributing factors [42, 43]. Therefore, future research should focus on methods of improving intestinal flora with the overall aim of regulating intestinal homeostasis.

2.5. Liver Cancer. Recent studies indicate that changes in the composition of the intestinal microbiota and their metabolites also represent a significant risk factor for HCC $[44,45]$. Intestinal microbiota have multiple roles and can regulate the immune response, while also promoting the development of cancer and the anti-tumor response following immunotherapy and chemotherapy $[16,46]$. A large, crossregional report [45] from China found that fecal microbial diversity decreased in patients with liver cirrhosis compared with healthy subjects, although it was greater in patients with liver cirrhosis compared with those with early HCC. This suggests that altered microbial communities may play an important role in the occurrence and development of HCC. Compared with patients with liver cirrhosis, 13 genera, including Gemmiger, Parabacteroides, Paraprevotella, and Clostridium XVIII, were enriched in early HCC patients. In patients with early HCC, Ruminococcus, Oscillibacter, Faecalibacterium, Clostridium IV, and Coprococcus (which produce butyrate) were lower, while Klebsiella and Haemophilus (which can produce LPS) were higher. The damage to the intestinal mucosa and barrier function in early HCC is related to a decrease in butyrate-producing bacteria and increased levels of LPS-producing bacteria. Deoxycholic acid (DCA) is a metabolite of intestinal bacteria such as Clostridium cluster XI and XIVa, which can cause DNA damage, playing a key role in the development of obesity-related HCC [47]. A case-control study reported that higher serum concentrations of TMAO were associated with increased HCC risk. Higher levels of serum choline resulted in a lower risk of PLC [48].

HCC is an end-stage liver disease with high mortality, limited effective treatments, and a low clinical cure rate. Understanding the microbiome may be of great value to research into the mechanism, early diagnosis, and clinical treatment of HCC. Therefore, the study of intestinal flora in HCC is of critical importance and may provide potential target(s) for adjuvant therapy in HCC treatment regimes.

\section{Link between Gut Microbiota, Liver Disease, and Related Risk Factors}

The pathophysiology of different liver diseases exhibits some common characteristics. Pathogenic risk factors alter the composition and quantity of gastrointestinal microflora. 
Factors including inflammation, endogenous ethanol production, fat metabolism, bile acid metabolism, and endotoxin production are influenced by intestinal microbiota, and their metabolites are related to the occurrence and development of liver diseases (Figure 1). Where the expression of proinflammatory factors in the liver is promoted, it causes activation of intestinal inflammation, damage to the intestinal barrier, and promotion of the development of endotoxins and their release into the blood, resulting in further progression of the liver disease (Table 1).

3.1. Inflammation. Inflammation is among the most common symptoms of viral, alcoholic, or fatty liver disease. It occurs at all stages and is closely related to fibrosis, cirrhosis, cancer, and failure of the liver [50]. Microbial pathogens or danger signals from the host can trigger inflammation. The hepatitis virus is a common cause of liver inflammation, and endogenous bacteria are responsible for the majority of liver diseases [51].

Local inflammation, systemic inflammation (SI), endotoxemia, and complications such as SBP and HE are all closely linked to the gut microbiota [52]. Infiltration of inflammatory cells is common in chronic liver disease. A murine model of NAFLD indicated that there was an increase in SI combined with increased levels of TNF- $\alpha$ and MCP-1 [53]. According to the systemic inflammation hypothesis, chronic inflammation induces the occurrence of ACLF due to the translocation of PAMPs from the intestine and/or DAMP production derived from the damaged liver. Claria et al. [54] found that the severity of SI exhibited positive correlation with ACLF severity and that IL-8, IL-6, and HNA2 levels were directly correlated with the 28- and 90-day mortality of patients. Recent human and animal studies have demonstrated that changes in the relative abundance and composition of the intestinal microbiome affect inflammation and the manifestation of liver disease, and its prognosis. Increased BT is another feature of chronic and end-stage liver disease, which not only contributes to the entry of bacteria and their components, such as LPS, into the portal vein circulation, but also increases the expression of specific receptors such as TLR4 that activates the inflammatory factors TNF, IL-1, and IFN [55].

3.2. Ethanol. In the 1850 s, scientists discovered that the human body naturally produces small quantities of ethanol, termed EnEth [56]. Ethanol has a direct toxic effect on the liver and can cause hepatocyte degeneration and necrosis. Patients with liver injury were found to have a higher prevalence of intestinal diseases, EnEth production, intestinal permeability, and bacterial translocation [28, 57]. In addition to being a hepatotoxin, there is considerable evidence that ethanol is also a carcinogen [57].

The increased abundance of Firmicutes and Bacteroidetes was observed in patients with NASH and obesity, which was accompanied by higher serum ethanol levels, indicating that Escherichia coli may contribute to elevated blood ethanol levels [58]. Increased microbial ethanol production may lead to a chronic, low-level exposure to the hepatotoxin, exposing the body to the risk of inflammation and hepatitis. A recent study indicated that EnEth produced by HiAlc bacteria is an important factor in the induction of lipid accumulation and mitochondrial damage in hepatocytes [28]. In the absence of a history of liver disease, acute and high levels of alcohol intake can also cause damage to the intestinal mucosa and barrier, increasing the level of bacteria and related components. In addition, alcohol is a recognized carcinogen, the risk of which starts at a dose of $10 \mathrm{~g} / 1 \mathrm{unit} /$ day. Acetaldehyde formation leads to the direct damage to proteins and DNA, while increased ROS production further exacerbates damage to antioxidant defense and DNA repair mechanisms. Changes in ethanol levels can also affect the immune system and induce chronic inflammation, all of which are related to the mechanisms of alcohol-mediated HCC [57].

3.3. Lipid Metabolism. The liver plays an important role in the synthesis, decomposition, metabolism, and storage of lipids and lipoproteins. In general, the levels of lipids and lipoproteins decrease with the increasing severity of liver disease [59]. However, specific analyses should be performed depending on disease etiology. Differences in the abundance, structure, and quantity of the gut microbiome influence the regulation of lipids and related metabolites.

Just et al. found that the decreased relative abundance of Lachnospiraceae was associated with reduced cholesterol biosynthesis and elevated cholesterol levels in the liver [60]. In contrast, An et al. found that Lactobacillus and Bifidobacterium reduce cholesterol, triglycerides, and LDL levels in the blood circulation, in addition to increasing HDL levels [61]. Changes in the intestinal flora as NAFLD progresses can interfere with hepatic lipid metabolism, the promotion of lipid accumulation, and lipotoxicity [62]. Levels of free fatty acids (FFAs) and bacterial metabolites such as LPS can activate TLR4 and induce the transduction of relatively proinflammatory signaling pathways [55]. In liver cirrhosis, it is common for lower levels of cholesterol, triglycerides, and lipoproteins, but the relationship between the severity of cirrhosis and lipid levels varies and is dependent on the different underlying causes of the disease. HDL concentrations in patients with nonalcoholic liver cirrhosis increase in accordance with disease severity, whereas LDL levels decrease with disease progression. In alcoholic liver cirrhosis, only triglyceride levels change as the disease progresses [63].

3.4. Bile Acid Metabolism. Intestinal blood accounts for $70 \%$ of the whole liver blood supply, and bile acids (BAs) can be recycled back to the liver through the liver and intestines, indicating that BAs link gut microbiota to liver and intestinal metabolism, thereby affecting gastrointestinal motility, intestinal permeability, and carcinogenesis.

The quantity of lactobacillus DNA in fecal samples has been shown to display a positive correlation with the severity of liver steatosis in mice, suggesting that Lactobacillus may increase the risk of fatty liver disease by influencing lipid metabolism through their impact on bile acid metabolism [64]. The similarity between the change in intestinal 


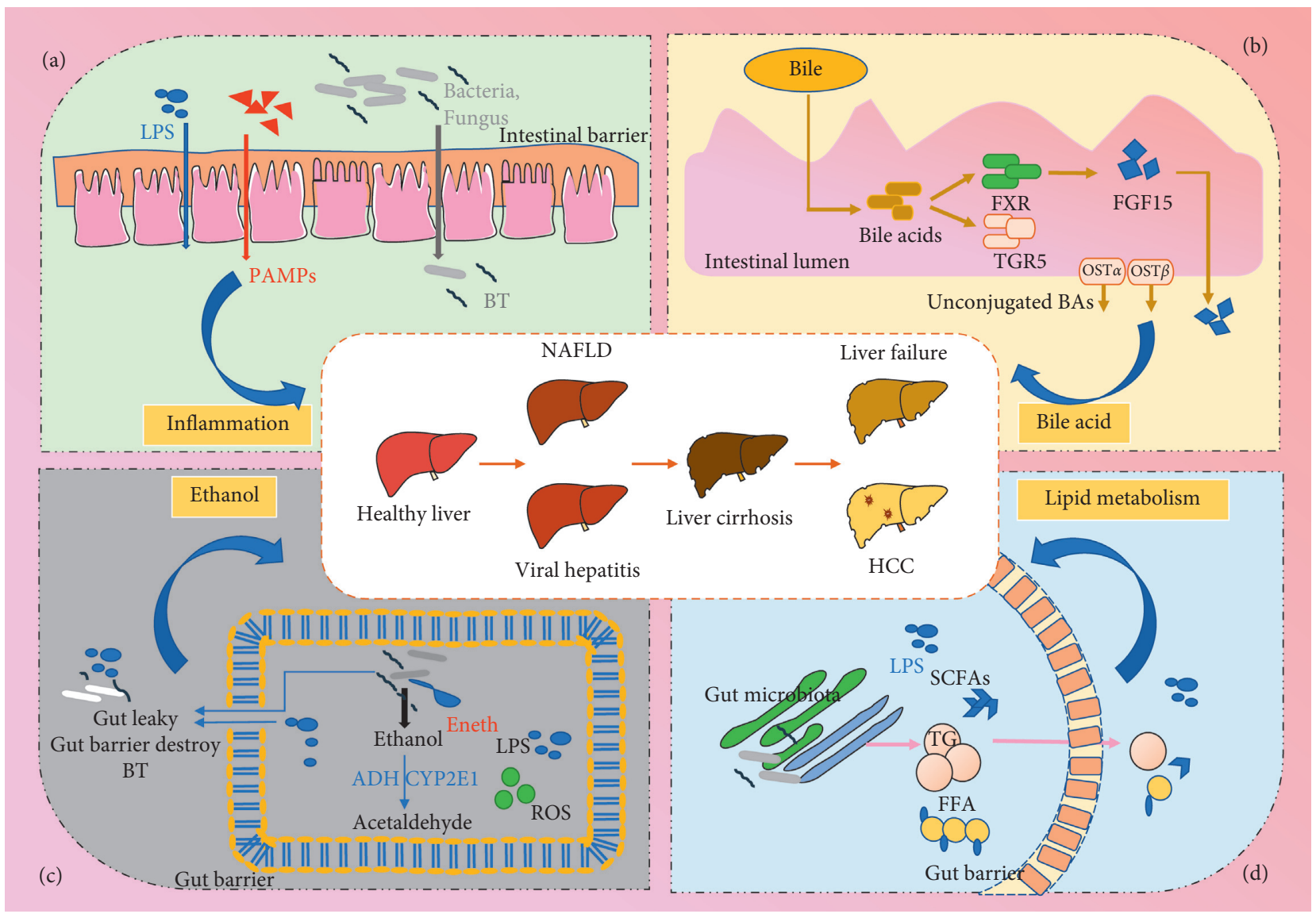

FiguRE 1: The link between gut microbiota and liver disease risk factors.Inflammation, EnEth, lipid metabolism, bile acid metabolism, and endotoxin levels are the common risk factors for liver diseases induced by intestinal microbiotas and their metabolites. (a) Inflammation: it is one of the most typical features of liver disease and occurs at all stages of disease development. (b) Bile acid metabolism: bile acid is an important part of bile, and intestinal floras regulate its metabolism through the FXR/TGR5 pathway. (c) Ethanol: in addition to exogenous alcohol intake, intestinal flora also can produce a large amount of ethanol (EnEth), affecting intestinal barrier and BT. (d) Lipid metabolism: gut microbiota influence on lipid metabolism may be mediated through metabolites and LPS. NAFLD, nonalcoholic fatty liver disease; HCC, hepatocellular carcinoma; LPS, lipopolysaccharides; PAMPs, pathogen-associated molecular patterns; BT, bacteria translocation; FXR, farnesoid X receptor; EnEth, endogenous ethanol; ROS, oxidative stress, and reactive oxygen species; SCFAs, short-chain fatty acids; TG, triglycerides; FFA, free fatty acids.

TABLE 1: Interaction between the intestinal microbiota and liver diseases.

\begin{tabular}{|c|c|c|c|c|c|}
\hline Disease & Subjects & Gut microbiota & $\begin{array}{l}\text { Gut microbial } \\
\text { metabolites }\end{array}$ & Potential mechanisms & Ref. \\
\hline \multirow[b]{2}{*}{$\begin{array}{l}\text { Viral } \\
\text { hepatitis }\end{array}$} & CHC patients & $\begin{array}{c}\uparrow \text { Streptococcus and Lactobacillus; } \\
\downarrow \downarrow \text { Clostridiales }\end{array}$ & $\uparrow \mathrm{pH}$ & $\begin{array}{c}\text { Gut dysbiosis, Viridans } \\
\text { streptococci } \uparrow\end{array}$ & $\begin{array}{c}\text { Inoue et al. } \\
{[20]}\end{array}$ \\
\hline & $\begin{array}{l}\text { HBVCLD } \\
\text { (CHB, LC) } \\
\text { patients }\end{array}$ & $\begin{array}{c}\uparrow \text { Enterobacteriaceae, Bacteroidetes/ } \\
\text { Firmicutes, Proteobacteria; } \\
\downarrow \text { Bifidobacteriaceae, Clostridiaceae, } \\
\text { Actinobacteria }\end{array}$ & None & $\begin{array}{c}\text { Glycan biosynthesis } \uparrow \text {, potential } \\
\text { bacteria } \uparrow \text {, potential beneficial } \\
\text { bacteria } \downarrow\end{array}$ & $\begin{array}{l}\text { Zeng et al. } \\
\quad[21]\end{array}$ \\
\hline \multirow[t]{2}{*}{ NAFLD } & $\begin{array}{l}\text { NAFLD } \\
\text { patients }\end{array}$ & $\begin{array}{c}\text { } \text { Bacteroidetes, Gram-negative/ } \\
\text { Gram-positive; } \downarrow \text { Firmicutes/ } \\
\text { Bacteroidetes, Firmicutes, } \\
\text { Lachnospiraceae, Ruminococcaceae, } \\
\text { Lactobacillaceae, } \\
\text { Peptostreptococcaceae }\end{array}$ & $\downarrow$ SCFAs & $\begin{array}{c}\text { SCFAs-producing bacteria } \downarrow \text {, } \\
\text { beneficial bacterial, potentially } \\
\text { opportunistic pathogenic } \\
\text { lipopolysaccharide-producing } \\
\text { bacteria } \uparrow\end{array}$ & $\begin{array}{l}\text { Wang et al. } \\
\quad[26]\end{array}$ \\
\hline & $\begin{array}{l}\text { HFD-induced } \\
\text { NAFLD mice }\end{array}$ & $\begin{array}{c}\uparrow \text { Lachnoclostridium, } \\
\text { Lachnospiraceae_UCG-006, } \\
\text { Mollicutes_RF9; } \downarrow \text { Blautia, } \\
\text { Akkermansia, Bacteroides }\end{array}$ & $\begin{array}{c}\uparrow \text { lithocholic acid, } \\
\text { deoxycholic acid; } \\
\downarrow \text { acetate, } \\
\text { propionate, butyrate }\end{array}$ & $\begin{array}{c}\text { Changes in secondary } \\
\text { metabolites (bile acid and } \\
\text { SCFAs) }\end{array}$ & Li et al. [27] \\
\hline
\end{tabular}


TABLE 1: Continued.

\begin{tabular}{|c|c|c|c|c|c|}
\hline Disease & Subjects & Gut microbiota & $\begin{array}{c}\text { Gut microbial } \\
\text { metabolites }\end{array}$ & Potential mechanisms & Ref. \\
\hline \multirow{3}{*}{$\begin{array}{l}\text { Liver } \\
\text { cirrhosis }\end{array}$} & In vitro & $\uparrow$ Hi Alc K. pneumoniae & $\uparrow$ EnEth & $\begin{array}{l}\text { Mitochondrial dysfunction } \uparrow, \\
\quad \text { lipid accumulation } \downarrow\end{array}$ & $\begin{array}{l}\text { Chen et al. } \\
\text { [28] }\end{array}$ \\
\hline & $\begin{array}{l}\text { Liver cirrhosis } \\
\text { patients }\end{array}$ & $\begin{array}{c}\uparrow \text { Enterococcaceae, Staphylococcaceae, } \\
\text { Enterobacteriaceae; } \downarrow \text { Clostridiales } \\
\text { XIV, Ruminococcaceae, } \\
\text { Lachnospiraceae, Veillonellaceae, } \\
\text { Porphyromonadaceae, }\end{array}$ & None & $\begin{array}{c}\mathrm{CDR} \downarrow, \mathrm{LPS} \uparrow, \text { inflammatory } \\
\text { response } \uparrow\end{array}$ & $\begin{array}{l}\text { Bajaj et al. } \\
\text { [32] }\end{array}$ \\
\hline & $\begin{array}{l}\text { Liver cirrhosis } \\
\text { patients with/ } \\
\text { without HE } \\
\text { patients }\end{array}$ & $\begin{array}{c}\uparrow \text { Staphylococcaceae; Enterococcaceae, } \\
\text { Porphyromonadaceae, } \\
\text { Lactobacillaceae; } \downarrow \text { Lactobacillus, } \\
\text { Eubacterium }\end{array}$ & $\begin{array}{c}\uparrow \text { endotoxin, } \\
\text { ammonia; } \downarrow \text { SCFAs }\end{array}$ & $\begin{array}{c}\text { Systemic inflammation } \uparrow \text {, } \\
\text { ammonia } \uparrow \text {, neuronal and } \\
\text { astrocytic dysfunction } \uparrow\end{array}$ & $\begin{array}{l}\text { Ahluwalia } \\
\text { et al. [35] }\end{array}$ \\
\hline \multirow{2}{*}{$\begin{array}{l}\text { Liver } \\
\text { failure }\end{array}$} & ACLF patients & $\begin{array}{l}\uparrow \text { Pasteurellaceae, Streptococcaceae, } \\
\text { Enterococcaceae; } \downarrow \text { Bacteroidaceae, } \\
\text { Ruminococcaceae, Lachnospiraceae }\end{array}$ & None & Systemic inflammation $\uparrow$ & $\begin{array}{l}\text { Chen et al. } \\
\text { [40] }\end{array}$ \\
\hline & $\begin{array}{c}\text { Rat model of } \\
\text { acute liver } \\
\text { failure }\end{array}$ & $\begin{array}{c}\uparrow \text { Acetatifactor muris, Butyricimonas } \\
\text { spp., Oscillibacter spp.; } \downarrow \text { Alloprevotella } \\
\text { spp. }\end{array}$ & None & probiotics $\downarrow$ & $\begin{array}{l}\text { Wang et al. } \\
{[49]}\end{array}$ \\
\hline \multirow{2}{*}{$\begin{array}{l}\text { Liver } \\
\text { cancer }\end{array}$} & $\begin{array}{l}\text { Liver cancer } \\
\text { patients }\end{array}$ & $\begin{array}{c}\uparrow \text { Klebsiella, Haemophilus; } \downarrow \text { Alistipes, } \\
\text { Phascolarctobacterium, } \\
\text { Ruminococcus, Oscillibacter, } \\
\text { Faecalibacterium, Clostridium IV }\end{array}$ & $\uparrow L P S, \downarrow$ butyrate & $\begin{array}{c}\text { LPS-producing bacteria } \uparrow ; \\
\text { butyrate-producing bacteria } \downarrow\end{array}$ & $\begin{array}{l}\text { Ren et al. } \\
\quad[45]\end{array}$ \\
\hline & $\begin{array}{l}\text { Obesity- } \\
\text { associated } \\
\text { HCC mice }\end{array}$ & $\uparrow$ Clostridium cluster XI, XIVa & $\uparrow$ deoxycholic acid & Gram-positive bacteria $\uparrow$ & $\begin{array}{l}\text { Yoshimoto } \\
\text { et al. [47] }\end{array}$ \\
\hline
\end{tabular}

CHC: chronic hepatitis C; HBVCLD: HBV-induced chronic liver disease; SCFAs: short-chain fatty acids; NAFLD: nonalcoholic fatty liver disease; HFD: highfat diet; EnEth: endogenous ethanol; BT: bacteria translocation; LPS: lipopolysaccharide.

microbes in HFD-fed rats and NASH patients suggests that HFD may be an important cause of the initiation of elevated intestinal bile acid [65]. An additional study compared gut microbiota and BA levels in healthy patients with NASHnon-HCC and NASH-HCC patients, finding that there was a gradual decrease in the abundance of Bacteroidetes and Actinobacteria, with a progressive increase in Lactobacillus. A separate study found that intestinal microbiota use bile acids as messengers to control CXCL16-dependent accumulation of liver NKT cells, which play a role in anti-tumor immunity and are active against primary and metastatic liver tumors [66]. Bile acids play an important role in liver regeneration. In the absence of intestinal bile, liver regeneration in rats has been shown to be impeded, with low levels of bile acids impairing liver regeneration and high levels promoting it $[67,68]$.

\section{Intervention Therapy Using Traditional Chinese Medicine (TCM)}

As a treasure of Chinese culture, TCM is widely accepted in China and East Asia due to its remarkable ability to cure diseases with few side effects. It has become increasingly popular in both Western countries and the rest of the world [69]. A number of studies have demonstrated that individual ingredients or compounds in TCM can inhibit the growth of pathogens, enhance the growth of beneficial bacteria, restore the diversity of intestinal flora, enhance intestinal barrier function, and improve immune function [14, 70-75]
(Figure 2, Table 2). In addition, polyphenols, dietary prebiotic fiber, and probiotic components are widely found in TCM and have been found to regulate the gut microbiota.

4.1. TCM Regulates the Composition of Intestinal Flora. Oral administration is among the most common methods of receiving TCM, and thus, it will inevitably interact with the intestinal flora [85]. TCM may directly or indirectly regulate the composition of the gut microbiota and maintain its dynamic balance via the promotion, inhibition, or elimination of bacterial growth and new colonization [13].

A number of studies have demonstrated that TCM can affect the progression of liver disease by altering the composition of the intestinal microbiome. Polyphenol-rich loquat fruit extract (LFP) regulates the microbiome by maintaining the ratio of intestinal Firmicutes/Bacteroidetes, thereby reducing oxidative stress and inflammation, decreasing lipid metabolism disorders, and alleviating highfructose diet- (HF-) induced NAFLD [76]. Water-insoluble polysaccharides, consumed as prebiotics, isolated from the sclerotium of Poria cocos, can increase butyrate production by increasing the abundance of Lachnospiraceae, Clostridium $X I V A$ and $I V$, thereby enhancing the integrity of the intestinal mucosa [72]. The abundance of Clostridium XIV A and $I V$ has been shown to negatively correlate with liver steatosis [86]. In rats with liver cirrhosis induced by carbon tetrachloride $\left(\mathrm{CCl}_{4}\right)$, Artesunate (an extract of Artemisia annua) has been shown to increase levels of Lactobacillus and Eubacterium, thereby reducing the concentration of 


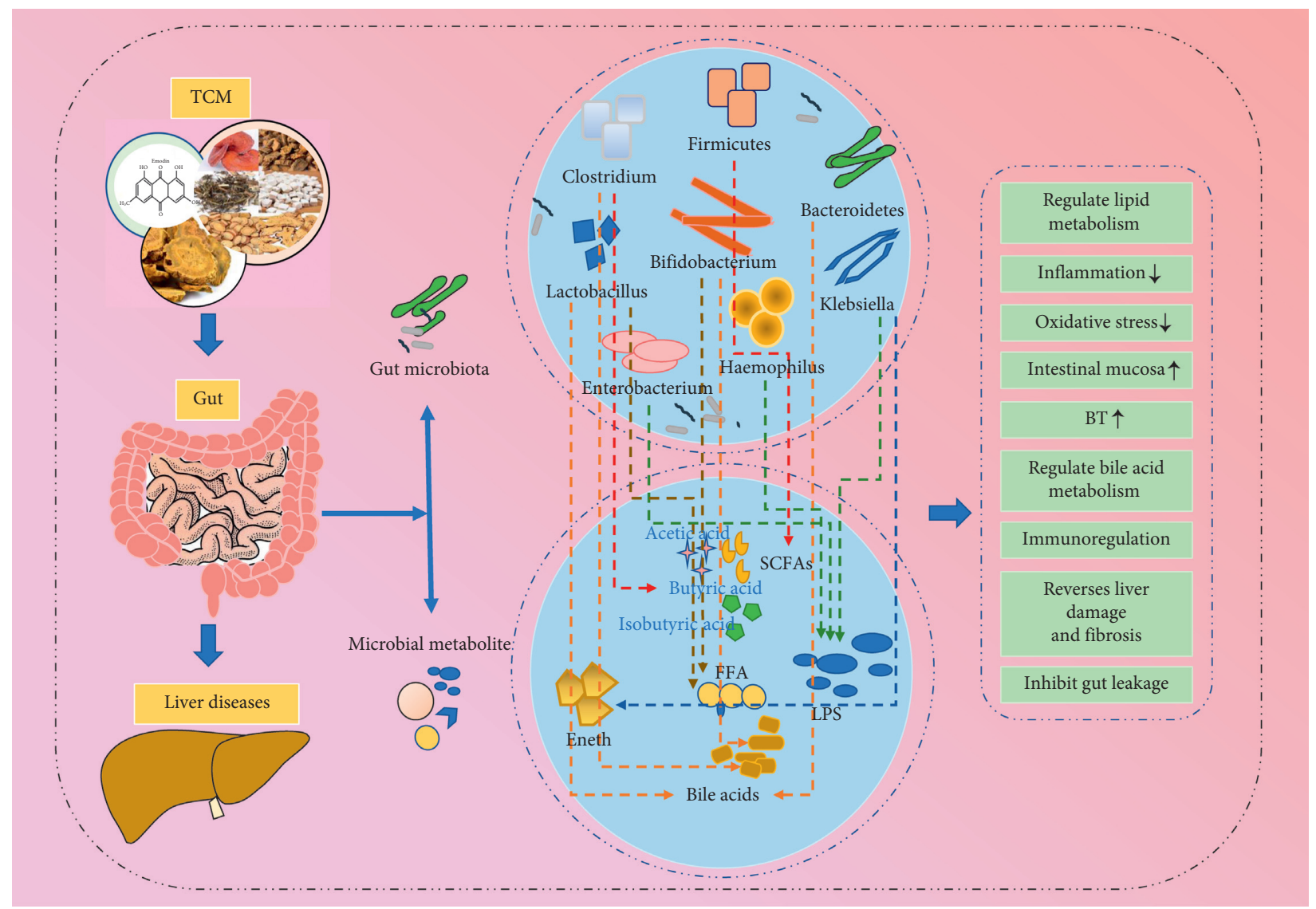

FIGURE 2: TCM affects liver disease progression by regulating intestinal microbiotas. The composition of intestinal microbiotas and their metabolites can be regulated by TCM. For example, Chinese herbs can increase SCFA levels by promoting abundance of Clostridium and Firmicutes, elevate bile acid levels by increasing Lactobacillus and Bifidobacterium abundance, and reduce levels of LPS and inflammatory factors by decreasing populations of Klebsiella and Haemophilus. The specific mechanisms include reducing inflammatory injury and oxidative stress, regulating body immunity, improving lipid metabolism, protecting intestinal barrier, and reversing hepatic fibrosis. TCM, traditional Chinese medicine; LPS, lipopolysaccharides; BT, bacterial translocation; EnEth, endogenous ethanol; SCFAs, short-chain fatty acids; FFA, free fatty acids.

TABLE 2: Mechanism by which TCM regulates the composition and metabolism of intestinal flora.

\begin{tabular}{|c|c|c|c|c|c|c|}
\hline $\begin{array}{l}\text { Herbs/ } \\
\text { decoction }\end{array}$ & Source/component & Model & Microbial target & $\begin{array}{l}\text { Microbial } \\
\text { metabolite }\end{array}$ & Related mechanism & Ref. \\
\hline $\begin{array}{l}\text { Water- } \\
\text { insoluble } \\
\text { polysaccharide }\end{array}$ & Poria cocos & $\begin{array}{l}\mathrm{ob} / \mathrm{ob} \\
\text { mice }\end{array}$ & $\begin{array}{c}\uparrow \text { Lachnospiraceae, } \\
\text { Clostridium, Bacteroidetes, } \\
\text { Alloprevotella, } \\
\text { Parabacteroides, Clostridium } \\
\text { IV, Ruminococcus, } \\
\text { Bacteroides; } \downarrow \text { Megamonas, } \\
\text { Proteus }\end{array}$ & $\begin{array}{l}\uparrow S C F A s, \\
\text { butyrate }\end{array}$ & $\begin{array}{l}\text { Regulate lipid and } \\
\text { glucose metabolism }\end{array}$ & $\begin{array}{c}\text { Sun et al. } \\
{[72]}\end{array}$ \\
\hline $\begin{array}{l}\text { Qushi huayu } \\
\text { decoction }\end{array}$ & $\begin{array}{l}\text { Artemisiae scopariae } \\
\text { herba, Polygoni } \\
\text { cuspidati rhizome et } \\
\text { radix, Curcumae } \\
\text { longae rhizome }\end{array}$ & $\begin{array}{l}\text { High-fat } \\
\text { diet }\end{array}$ & $\begin{array}{c}\uparrow \text { Clostridium XIV a, } \\
\text { Clostridium IV Odoribacter; } \\
\downarrow \text { Rikenella, Tyzzerella, } \\
\text { Intestinibacter, Romboutsia, } \\
\text { Lachnospiraceae }\end{array}$ & $\downarrow$ LPS & $\begin{array}{c}\text { Inhibit LPS gut-leakage, } \\
\text { downregulate intestinal } \\
\text { MAPK pathway }\end{array}$ & $\begin{array}{l}\text { Leng et al. } \\
\text { [73] }\end{array}$ \\
\hline $\begin{array}{l}\text { Polyphenol- } \\
\text { rich loquat fruit } \\
\text { extract }\end{array}$ & Loquat fruit & $\begin{array}{l}\text { High- } \\
\text { fructose } \\
\text { diet }\end{array}$ & $\begin{array}{c}\uparrow \text { Bacteroidetes, Firmicutes, } \\
\text { Proteobacteria, } \\
\text { Actinobacteria; } \downarrow \text { Firmicutes/ } \\
\text { Bacteroidetes ratio }\end{array}$ & None & $\begin{array}{l}\text { Reduce oxidative stress } \\
\text { and inflammation, } \\
\text { decrease lipid } \\
\text { metabolism disorders }\end{array}$ & $\begin{array}{l}\text { Li et al. } \\
{[76]}\end{array}$ \\
\hline
\end{tabular}


TABLE 2: Continued.

\begin{tabular}{|c|c|c|c|c|c|c|}
\hline $\begin{array}{l}\text { Herbs/ } \\
\text { decoction }\end{array}$ & Source/component & Model & Microbial target & $\begin{array}{l}\text { Microbial } \\
\text { metabolite }\end{array}$ & Related mechanism & Ref. \\
\hline Artesunate & Artemisia aпnиа & $\begin{array}{l}\text { CCl4- } \\
\text { induced } \\
\text { liver } \\
\text { cirrhosis }\end{array}$ & $\uparrow$ Lactobacillus, Eubacterium & None & $\begin{array}{c}\text { Reduce injury to } \\
\text { intestinal mucosa, } \\
\text { decrease translocated } \\
\text { bacteria }\end{array}$ & $\begin{array}{l}\text { Chen et al. } \\
\text { [77] }\end{array}$ \\
\hline $\begin{array}{l}\text { Shenling Baizhu } \\
\text { powder }\end{array}$ & $\begin{array}{l}\text { Ginseng radix et } \\
\text { rhizoma, Poria, } \\
\text { Atractylodis } \\
\text { macrocephalae } \\
\text { rhizoma, Dioscoreae } \\
\text { rhizoma, Lablab } \\
\text { semen album, } \\
\text { Nelumbinis semen, } \\
\text { Glycyrrhizae radix } \\
\text { et rhizoma } \\
\text { praeparata cum } \\
\text { melle, Coicis semen, } \\
\text { Platycodonis radix, } \\
\text { Amomi fructus }\end{array}$ & $\begin{array}{l}\text { HFD- } \\
\text { induced } \\
\text { NAFLD }\end{array}$ & $\uparrow$ Bifidobacteria, Anaerobe & $\uparrow$ SCFAs, $\downarrow$ LPS & $\begin{array}{c}\text { Inhibit TLR4/MYD88 } \\
\text { pathway }\end{array}$ & $\begin{array}{l}\text { Zhang } \\
\text { et al. [78] }\end{array}$ \\
\hline $\begin{array}{l}\text { Sanwei ganjiang } \\
\text { powder }\end{array}$ & $\begin{array}{c}\text { Zingiberis rhizoma, } \\
\text { Alpinia katsumadai, } \\
\text { Myristica fragrans } \\
\text { houtt }\end{array}$ & $\begin{array}{l}\text { CCl4- } \\
\text { induced } \\
\text { chronic } \\
\text { liver } \\
\text { failure }\end{array}$ & $\begin{array}{c}\uparrow \text { Firmicutes, Lactobacillus; } \\
\downarrow \text { Firmicutes/Bacteroidetes } \\
\text { ratio, Bacteroidetes, } \\
\text { Actinobacteria, Coprococcus, } \\
\text { Ruminococcus, Sutterella }\end{array}$ & $\begin{array}{l}\text { } C Y P 7 A 1 \\
\text { NTCP, Mrp2, } \\
\text { BESP }\end{array}$ & $\begin{array}{c}\text { Regulate bile acid } \\
\text { metabolism, increased } \\
\text { the expression of Nrf2, } \\
\text { decrease inflammatory } \\
\text { response }\end{array}$ & $\begin{array}{l}\text { Li et al. } \\
\text { [79] }\end{array}$ \\
\hline Rhubarb extract & Rheum palmatum & $\begin{array}{l}\text { Mouse } \\
\text { model of } \\
\text { binge } \\
\text { drinking }\end{array}$ & $\begin{array}{c}\uparrow \text { Parabacteroides goldsteinii; } \\
\downarrow \text { Lachnospiraceae, } \\
\text { Prevotellaceae, Akkermansia, }\end{array}$ & $\downarrow$ LPS & $\begin{array}{l}\text { Improve gut barrier } \\
\text { function, relieve } \\
\text { oxidative stress and } \\
\text { inflammation, inhibit } \\
\text { TLR4 and NADPH } \\
\text { oxidase }\end{array}$ & $\begin{array}{l}\text { Neyrinck } \\
\text { et al. [80] }\end{array}$ \\
\hline $\begin{array}{l}\text { Sijunzi } \\
\text { decoction }\end{array}$ & $\begin{array}{c}\text { Panax ginseng, } \\
\text { Atractylodes } \\
\text { macrocephala } \\
\text { Koidz, the } \\
\text { sclerotium of the } \\
\text { fungus, Poria cocos, } \\
\text { Glycyrrhiza } \\
\text { uralensis fisch }\end{array}$ & In vitro & $\begin{array}{c}\uparrow \text { Lactobacillus, Pediococcus, } \\
\text { Sutterella; } \downarrow \text { Paraprevotella, } \\
\text { Bacteroides, Streptococcus, } \\
\text { Clostridium, Ruminococcus, } \\
\text { Butyricimonas, }\end{array}$ & $\begin{array}{l}\text { †acetic acid, } \\
\text { total acid } \\
\downarrow \text { propionic } \\
\text { acid, butyric } \\
\text { acid }\end{array}$ & $\begin{array}{l}\text { Immunomodulatory } \\
\text { function }\end{array}$ & $\begin{array}{l}\text { Gao et al. } \\
{[81]}\end{array}$ \\
\hline Resistant starch & Purple yam & $\begin{array}{l}\text { High-fat } \\
\text { diet }\end{array}$ & $\begin{array}{c}\uparrow \text { Bifidobacteria, Lactobacillus, } \\
\text { Coprococcus, Allobaculum; } \\
\downarrow \text { Parabacteroides, Dorea }\end{array}$ & None & $\begin{array}{l}\text { Ameliorate lipid } \\
\text { metabolism }\end{array}$ & $\begin{array}{l}\text { Li et al. } \\
\text { [82] }\end{array}$ \\
\hline $\begin{array}{l}\text { Ethanol extract } \\
\text { of Ganoderma } \\
\text { lucidum (GL95) }\end{array}$ & G. lucidum & $\begin{array}{l}\text { High-fat } \\
\text { diet }\end{array}$ & $\begin{array}{c}\uparrow \text { Alistipes, Peptococcaceae, } \\
\text { Defluviitalea and } \\
\text { Alloprevotella; } \\
\downarrow \text { Phascolarctobacterium, } \\
\text { Clostridium XVIII }\end{array}$ & $\begin{array}{l}\uparrow \text { Bile acid, } \\
\text { SCFAs, } \\
\text { HMGCR, } \\
\text { CYP7A1, } \\
\text { PPAR } \alpha, \text { ApoB; } \\
\downarrow \text { FAS, ACAT2, } \\
\text { SREBP-1C, } \\
\text { HMGCR }\end{array}$ & $\begin{array}{l}\text { Improve lipid } \\
\text { metabolism }\end{array}$ & $\begin{array}{l}\text { Guo et al. } \\
\text { [83] }\end{array}$ \\
\hline Ursolic acid & $\begin{array}{l}\text { Natural pentacyclic } \\
\text { triterpenoid } \\
\text { compound derived } \\
\text { from Chinese } \\
\text { medicine plants }\end{array}$ & $\begin{array}{l}\text { CCl4- } \\
\text { induced } \\
\text { liver } \\
\text { fibrosis }\end{array}$ & $\begin{array}{c}\uparrow \text { Firmicutes, Bacteroidales, } \\
\text { and Lachnospiraceae } \\
\downarrow \text { Verrucomicrobia }\end{array}$ & None & $\begin{array}{l}\text { Inhibit the NOX4/ROS } \\
\text { and RhoA/ROCK1 } \\
\text { signalling pathways, } \\
\text { reverses liver damage } \\
\text { and fibrosis }\end{array}$ & $\begin{array}{l}\text { Wan et al. } \\
\text { [84] }\end{array}$ \\
\hline
\end{tabular}

SCFAs: short-chain fatty acids; NAFLD: nonalcoholic fatty liver disease; HFD: high-fat diet; LPS: lipopolysaccharide; MAPK: mitogen-activated protein kinase.

proinflammatory IL- 6 and TNF- $\alpha$, reducing injury to the intestinal mucosa, and decreasing the numbers of translocated bacteria [77]. TCM compounds, such as Qushi
Huayu decoction and Erzhi pills, are also capable of modifying the composition of the intestinal flora, which can affect fatty liver disease [73, 87]. 
4.2. TCM Regulates the Metabolism of the Intestinal Flora. The principal gut flora metabolites include SCFAs, secondary bile acid, vitamins, polyphenols, lipids, and indole derivatives, which participate in a variety of biological functions $[88,89]$. TCMs can regulate the metabolism of the gut microbiome by modulation of its composition and/or by adjusting the activity of enzymes produced by catalytic metabolites [90]. Because TCM can promote, inhibit, eliminate, or colonize particular bacterial species, it, therefore, has the ability to regulate the metabolites of the intestinal microbiome.

Shenling Baizhu powder was found to enhance the overall abundance of the intestinal microflora in a rat model of NAFLD, and the relative abundance of Bifidobacteria and Anaerobe also increased, enhancing levels of SCFA [78]. Similarly, Berberine and Stachyose also increase the levels of SCFAs produced by a number of bacteria (Akkermansia, Firmicutes, and Bacteroidetes) in mice fed a HFD [91, 92]. LPS is a glycolipid found on the outer membrane of Gramnegative bacteria, and its increase is known to be an important cause of endotoxemia. Dachengqi decoction, recorded in the Treatise on Febrile and Miscellaneous Disease, is a typical prescription for catharsis. Modern studies have found that it reduces both endotoxin levels and gut inflammation [93]. In a $\mathrm{CCl}_{4}$-induced model of chronic liver injury, proteins related to the synthesis (CYP7A1), excretion, and reabsorption of bile acids (such as NTCP, Mrp2, and BESP) were upregulated following the administration of Sanwei Ganjiang powder [79].

\subsection{Mechanisms of the Regulation of the Gut Microbiome by} Traditional Chinese Medicine. Through the theories of TCM as "syndrome differentiation and treatment" and the "concept of wholism," the relationship between liver diseases and intestinal flora is inseparable. The majority of Chinese herbs exhibit the mechanism (termed "gongxiao" in Chinese) of promoting probiotic action and inhibition of pathogens, with synergy occurring with two or more compatible Chinese medicines [94]. The intestinal flora may, therefore, be a promising novel pharmacological target for the prevention and treatment of liver disease using TCM.

The mechanisms by which Chinese herbs regulate intestinal flora and thus affect the progression of liver disease involve a reduction in inflammatory injury and oxidative stress, which regulate an individual's immunity, reducing ammonia levels in serum, improving lipid metabolism, protecting the intestinal barrier, and reversing hepatic fibrosis, which are closely related to the TLR4 signaling pathway, and the involvement of NF- $\kappa \mathrm{B}$, ROS, NOX4/ROS, and RhoA/ROCK1 [78, 80-84, 91]. Rhubarb extract affects antimicrobial peptide production and the stability of the intestinal environment, via the downregulation of inflammatory and oxidative marker expression, such as TLR4 and NADPH oxidase, which strengthens the intestinal barrier, thereby reducing liver damage caused by acute alcohol intake [80]. The microbial enzyme urease catalyzes the hydrolysis of urea to produce excessive ammonia, usually produced by Gram-negative Enterobacteriaceae, a number of anaerobes, and Gram-positive bacteria. Babaodan is able to reduce ammonia levels in the serum and inflammatory cytokines in rats with hepatic encephalopathy, possibly related to the TLR4/MyD88/NK- $\kappa \mathrm{B}$ signaling pathway. In animal models treated with a HFD, berberine was able to inhibit Akkermansia and increase the number of SCFAproducing bacteria, such as Lachnospiraceae, thereby reducing inflammation and improving intestinal epithelial barrier function [91]. Shenling Baizhu powder is able to affect NAFLD progression via an increase in the abundance of beneficial bacteria and a reduction in the level of intestinal endotoxin [78]. In addition to reducing inflammatory injury, immune regulation is another important mechanism by which TCM prevents and treats liver diseases. S-3-1 [81], a homogeneous polysaccharide purified from Sijunzi decoction, has been shown to be immunomodulatory through an adjustment in the abundances of 9 intestinal genera (including Lactobacillus, Pediococcus, Sutterella, Paraprevotella, Bacteroides, Streptococcus, Clostridium, Ruminococcus, and Butyricimonas).

\section{Conclusions and Perspectives}

The discovery that gut flora has a significant metabolic influence in humans has opened a new paradigm in modern medical research. The processes of birth, aging, disease, and death are influenced by the balance of intestinal microbiota, which is related not only to intestinal health, but also to liver, brain, kidney, and organismal homeostasis. Additionally, researchers are now investigating the gut flora as a starting point for the exploration of biomarkers and treatments for many types of disease (such as cardiovascular diseases and liver disease) beyond the gut itself. This exploration is consistent with the Chinese approach of "holistic concept." Intestinal flora and their metabolites participate in the development of liver diseases, suggesting that the regulation of intestinal flora with TCM can play an important role in the treatment of liver disease. However, using the guiding TCM principle of "syndrome differentiation and treatment" and the overall concept of personalized therapy, it is necessary to systematically identify the differences in intestinal flora and their metabolites for the same TCM type of different liver diseases and different TCM types for the same disease. This will assist in establishing the mechanism by which intestinal microorganisms transform drugs into metabolites. Extensive DNA sequencing studies have expanded our understanding of the ecological and biological characteristics of the gut microbiota. Improved computational techniques, high throughput DNA sequencing, and study of the blood metabolome have deepened our understanding of gut microbiota. However, methodological differences among researchers have led to inconsistent data. Therefore, it is necessary to establish systematic and standardized research methods to study intestinal flora. Chinese herbs treat liver disease via regulation of the composition and metabolism of intestinal flora and have shown good clinical efficacy. Future research should focus on individual treatments and characterization of the relationship between intestinal flora, metabolites, and TCM's curative effect. In addition, due to 
the lack of active therapeutic effects of TCM on liver disease and an analysis of the specific mechanisms, further research (including basic research and clinical research) is still required.

\section{Abbreviations}

$\begin{array}{ll}\text { TCM: } & \text { Traditional Chinese medicine } \\ \text { NAFLD: } & \text { Nonalcoholic fatty liver disease } \\ \text { LPS: } & \text { Lipopolysaccharide } \\ \text { CHB: } & \text { Chronic hepatitis B } \\ \text { CHC: } & \text { Chronic hepatitis C } \\ \text { HCV: } & \text { Hepatitis C virus } \\ \text { HBV: } & \text { Hepatitis B virus } \\ \text { HBVCLD: } & \text { HBV-induced chronic liver disease } \\ \text { HCVCLD: } & \text { HCV-induced chronic liver disease } \\ \text { SCFAs: } & \text { Short-chain fatty acids } \\ \text { B/E: } & \text { Bifidobacterium/Enterobacteriaceae } \\ & \text { ratio } \\ \text { HFD: } & \text { High-fat diet } \\ \text { EnEth: } & \text { Endogenous ethanol } \\ \text { BT: } & \text { Bacteria translocation } \\ \text { ALF: } & \text { Acute liver failure } \\ \text { SALF: } & \text { Subacute liver failure } \\ \text { ACLF or SACLF: } & \text { Slow-onset acute (subacute) liver failure } \\ \text { CLF: } & \text { Chronic liver failure } \\ \text { HCC: } & \text { Hepatocellular carcinoma } \\ \text { PAMPs: } & \text { Pathogen-associated molecular patterns } \\ \text { DAMPs: } & \text { Damage-related molecular patterns } \\ \text { SBP: } & \text { Spontaneous bacterial peritonitis } \\ \text { HE: } & \text { Hepatic encephalopathy } \\ \text { SBP: } & \text { Spontaneous bacterial peritonitis } \\ \text { FFAs: } & \text { Free fatty acids } \\ \text { HF: } & \text { High-fructose diet. }\end{array}$

\section{Conflicts of Interest}

The authors declare no conflicts of interest.

\section{Authors' Contributions}

Tingshuai Wang and Shaodong Huang contributed equally to this work and are joint first authors of this article. Tingshuai Wang designed, wrote, and revised the manuscript. Dewen Mao conceived and proposed the study. Shaodong Huang designed the article structure. Cong $\mathrm{Wu}$, Rongzhen Rong, and $\mathrm{Na}$ Wang searched and analyzed a large number of published manuscripts. Minggang Wang revised the manuscript. All authors read and approved the final manuscript.

\section{Acknowledgments}

This study was supported financially by the National Natural Science Foundation of China (81960841 and, 82060848, 81774236.), the High-Level Innovation Team of Guangxi Province (2018GXNSFGA281002), and Guangxi Natural Science Foundation (2020GXNSFAA297070 and 2018GXNSFAA281047).

\section{References}

[1] J. Xiao, F. Wang, N.-K. Wong et al., "Global liver disease burdens and research trends: analysis from a Chinese perspective," Journal of Hepatology, vol. 71, no. 1, pp. 212-221, 2019.

[2] M. Verma, S. Kulshrestha, and A. Puri, "Genome sequencing," Methods in Molecular Biology, vol. 1525, pp. 3-33, 2017.

[3] F. Ji and R. I. Sadreyev, "RNA-seq: basic bioinformatics analysis," Current Protocols in Molecular Biology, vol. 124, no. 1, p. e68, 2018.

[4] I. Milosevic, A. Vujovic, A. Barac et al., "Gut-liver axis, gut microbiota, and its modulation in the management of liver diseases: a review of the literature," International Journal of Molecular Sciences, vol. 20, no. 2, p. 395, 2019.

[5] C. Acharya and J. S. Bajaj, "Gut microbiota and complications of liver disease," Gastroenterology Clinics of North America, vol. 46, no. 1, pp. 155-169, 2017.

[6] C. Acharya, S. E. Sahingur, and J. S. Bajaj, "Microbiota, cirrhosis, and the emerging oral-gut-liver axis," JCI Insight, vol. 2, no. 19, Article ID e94416, 2017.

[7] J. S. Bajaj, "Alcohol, liver disease and the gut microbiota," Nature Reviews Gastroenterology \& Hepatology, vol. 16, no. 4, pp. 235-246, 2019.

[8] V. B. Dubinkina, A. V. Tyakht, V. Y. Odintsova et al., "Links of gut microbiota composition with alcohol dependence syndrome and alcoholic liver disease," Microbiome, vol. 5, no. 1, p. 141, 2017.

[9] Z. Safari and P. Gérard, "The links between the gut microbiome and non-alcoholic fatty liver disease (NAFLD)," Cellular and Molecular Life Sciences, vol. 76, no. 8, pp. 1541-1558, 2019.

[10] J. Wang, Y.-K. Wong, and F. Liao, "What has traditional Chinese medicine delivered for modern medicine?" Expert Reviews in Molecular Medicine, vol. 20, p. e4, 2018.

[11] W.-J. Wang and T. Zhang, "Integration of traditional Chinese medicine and western medicine in the era of precision medicine," Journal of Integrative Medicine, vol. 15, no. 1, pp. 1-7, 2017.

[12] Y. Xie, F. Hu, D. Xiang et al., "The metabolic effect of gut microbiota on drugs," Drug Metabolism Reviews, vol. 52, no. 1, pp. 139-156, 2020.

[13] W. Feng, H. Ao, C. Peng, and D. Yan, "Gut microbiota, a new frontier to understand traditional Chinese medicines," Pharmacological Research, vol. 142, pp. 176-191, 2019.

[14] Q. Nie, H. Chen, J. Hu, S. Fan, and S. Nie, "Dietary compounds and traditional Chinese medicine ameliorate type 2 diabetes by modulating gut microbiota," Critical Reviews in Food Science and Nutrition, vol. 59, no. 6, pp. 848-863, 2019.

[15] X.-M. Wang, X.-B. Li, and Y. Peng, "Impact of Qi -invigorating traditional Chinese medicines on intestinal flora: a basis for rational choice of prebiotics," Chinese Journal of Natural Medicines, vol. 15, no. 4, pp. 241-254, 2017.

[16] A. Tripathi, J. Debelius, D. A. Brenner et al., "The gut-liver axis and the intersection with the microbiome," Nature Reviews Gastroenterology \& Hepatology, vol. 15, no. 7, pp. 397-411, 2018.

[17] R. Wiest, A. Albillos, M. Trauner, J. S. Bajaj, and R. Jalan, "Targeting the gut-liver axis in liver disease," Journal of Hepatology, vol. 67, no. 5, pp. 1084-1103, 2017.

[18] A. Tan-Garcia, L.-E. Wai, D. Zheng et al., "Intrahepatic $\mathrm{CD}^{2} 6^{+}$macrophages contribute to inflammation in advanced viral-related liver disease," Journal of Hepatology, vol. 67, no. 3, pp. 490-500, 2017. 
[19] Q. Zhu, P. Xia, X. Zhou et al., "Hepatitis B virus infection alters gut microbiota composition in mice," Frontiers Cellular Infection Microbiology, vol. 9, p. 377, 2019.

[20] T. Inoue, J. Nakayama, K. Moriya et al., "Gut dysbiosis associated with hepatitis C virus infection," Clinical Infectious Diseases, vol. 67, no. 6, pp. 869-877, 2018.

[21] Y. Zeng, S. Chen, Y. Fu et al., "Gut microbiota dysbiosis in patients with hepatitis B virus-induced chronic liver disease covering chronic hepatitis, liver cirrhosis and hepatocellular carcinoma," Journal of Viral Hepatitis, vol. 27, no. 2, pp. 143-155, 2020.

[22] R. Tojo, A. Suárez, M. G. Clemente et al., "Intestinal microbiota in health and disease: role of bifidobacteria in gut homeostasis," World Journal of Gastroenterology, vol. 20, no. 41, pp. 15163-15176, 2014.

[23] C. Hidalgo-Cantabrana, S. Delgado, L. Ruiz, P. Ruas-Madiedo, B. Sánchez, and A. Margolles, "Bifidobacteria and their health-promoting effects," Microbiology Spectrum, vol. 5, no. 3, 2017.

[24] M. A. Bailey and H. D. Holscher, "Microbiome-mediated effects of the mediterranean diet on inflammation," Advances in Nutrition, vol. 9, no. 3, pp. 193-206, 2018.

[25] W. Jia, G. Xie, and W. Jia, "Bile acid-microbiota crosstalk in gastrointestinal inflammation and carcinogenesis," Nature Reviews Gastroenterology \& Hepatology, vol. 15, no. 2, pp. 111-128, 2018.

[26] B. Wang, X. Jiang, M. Cao et al., "Altered fecal microbiota correlates with liver biochemistry in nonobese patients with non-alcoholic fatty liver disease," Scientific Reports, vol. 6, p. 32002, 2016.

[27] X. Li, Y. Wang, Y. Xing, R. Xing, Y. Liu, and Y. Xu, "Changes of gut microbiota during silybin-mediated treatment of highfat diet-induced non-alcoholic fatty liver disease in mice," Hepatology Research, vol. 50, no. 1, pp. 5-14, 2020.

[28] X. Chen, Z. Zhang, H. Li et al., "Endogenous ethanol produced by intestinal bacteria induces mitochondrial dysfunction in non-alcoholic fatty liver disease," Journal of Gastroenterology and Hepatology, vol. 35, no. 11, pp. 20092019, 2020.

[29] X. Tan, Y. Liu, J. Long et al., “Trimethylamine N-oxide aggravates liver steatosis through modulation of bile acid metabolism and inhibition of farnesoid X receptor signaling in nonalcoholic fatty liver disease," Molecular Nutrition and Food Research, vol. 63, Article ID e1900257, 2019.

[30] G. Baffy, "Potential mechanisms linking gut microbiota and portal hypertension," Liver International, vol. 39, no. 4, pp. 598-609, 2019.

[31] B. Simbrunner, M. Mandorfer, M. Trauner, and T. Reiberger, "Gut-liver axis signaling in portal hypertension," World Journal of Gastroenterology, vol. 25, no. 39, pp. 5897-5917, 2019.

[32] J. S. Bajaj, D. M. Heuman, P. B. Hylemon et al., "Altered profile of human gut microbiome is associated with cirrhosis and its complications," Journal of Hepatology, vol. 60, no. 5, pp. 940-947, 2014.

[33] N. Qin, F. Yang, A. Li et al., "Alterations of the human gut microbiome in liver cirrhosis," Nature, vol. 513, no. 7516, pp. 59-64, 2014.

[34] M. Priyadarshini, K. U. Kotlo, P. K. Dudeja, and B. T. Layden, "Role of short chain fatty acid receptors in intestinal physiology and pathophysiology," Comprehensive Physiology, vol. 8, pp. 1091-1115, 2018.
[35] V. Ahluwalia, N. S. Betrapally, P. B. Hylemon et al., "Impaired gut-liver-brain axis in patients with cirrhosis," Scientific Reports, vol. 6, p. 26800, 2016.

[36] P. Schwabl, E. Hambruch, B. A. Seeland et al., "The FXR agonist PX20606 ameliorates portal hypertension by targeting vascular remodelling and sinusoidal dysfunction," Journal of Hepatology, vol. 66, no. 4, pp. 724-733, 2017.

[37] E. Yigit, G. R. Feehery, B. W. Langhorst et al., "A microbiome DNA enrichment method for next-generation sequencing sample preparation," BMC Microbiology, vol. 115, 2016.

[38] I. Allali, J. W. Arnold, J. Roach et al., "A comparison of sequencing platforms and bioinformatics pipelines for compositional analysis of the gut microbiome," BMC Microbiology, vol. 17, p. 194, 2017.

[39] C. Wu, R. M. Bendriem, S. P. Garamszegi, L. Song, and C.-T. Lee, "RNA sequencing in post-mortem human brains of neuropsychiatric disorders," Psychiatry and Clinical Neurosciences, vol. 71, no. 10, pp. 663-672, 2017.

[40] Y. Chen, J. Guo, G. Qian et al., "Gut dysbiosis in acute-onchronic liver failure and its predictive value for mortality," Journal of Gastroenterology and Hepatology, vol. 30, no. 9, pp. 1429-1437, 2015.

[41] C. Bernsmeier, O. T. Pop, A. Singanayagam et al., "Patients with acute-on-chronic liver failure have increased numbers of regulatory immune cells expressing the receptor tyrosine kinase MERTK," Gastroenterology, vol. 148, no. 3, pp. 603-615, 2015.

[42] V. Cruz-Ramón, P. Chinchilla-López, O. Ramírez-Pérez, and N. Méndez-Sánchez, "Bile acids in nonalcoholic fatty liver disease: new concepts and therapeutic advances," Annals of Hepatology, vol. 16, pp. s58-s67, 2017.

[43] M. McMillin, G. Frampton, M. Quinn et al., "Bile acid signaling is involved in the neurological decline in a murine model of acute liver failure," The American Journal of $\mathrm{Pa}$ thology, vol. 186, no. 2, pp. 312-323, 2016.

[44] H. Gupta, G. S. Youn, M. J. Shin, and K. T. Suk, "Role of gut microbiota in hepatocarcinogenesis," Microorganisms, vol. 7, no. 5, 2019.

[45] Z. Ren, A. Li, J. Jiang et al., "Gut microbiome analysis as a tool towards targeted non-invasive biomarkers for early hepatocellular carcinoma," Gut, vol. 68, no. 6, pp. 1014-1023, 2019.

[46] M. L. Balmer, E. Slack, A. de Gottardi et al., "The liver may act as a firewall mediating mutualism between the host and its gut commensal microbiota," Science Translational Medicine, vol. 6, no. 237, 2014.

[47] S. Yoshimoto, T. M. Loo, K. Atarashi et al., "Obesity-induced gut microbial metabolite promotes liver cancer through senescence secretome," Nature, vol. 499, no. 7456, pp. 97-101, 2013.

[48] Z. Y. Liu, X. Y. Tan, Q. J. Li et al., “Trimethylamine N-oxide, a gut microbiota-dependent metabolite of choline, is positively associated with the risk of primary liver cancer: a case-control study," Nutrition and Metabolism (London), vol. 15, p. 81, 2018.

[49] K. Wang, L. Lv, R. Yan et al., "Bifidobacterium longum R0175 protects rats against d-galactosamine-induced acute liver failure," mSphere, vol. 5, no. 1, 2020.

[50] H. Tilg, P. D. Cani, and E. A. Mayer, "Gut microbiome and liver diseases,” Gut, vol. 65, no. 12, pp. 2035-2044, 2016.

[51] S. Piconese, I. Cammarata, and V. Barnaba, "Viral hepatitis, inflammation, and cancer: a lesson for autoimmunity," Journal of Autoimmunity, vol. 95, pp. 58-68, 2018. 
[52] T. Gong, L. Liu, W. Jiang, and R. Zhou, "DAMP-sensing receptors in sterile inflammation and inflammatory diseases," Nature Reviews Immunology, vol. 20, no. 2, pp. 95-112, 2020.

[53] S. Kakino, T. Ohki, H. Nakayama et al., "Pivotal role of TNF- $\alpha$ in the development and progression of nonalcoholic fatty liver disease in a murine model," Hormone and Metabolic Research, vol. 50, no. 1, pp. 80-87, 2018.

[54] J. Clària, R. E. Stauber, M. J. Coenraad et al., "Systemic inflammation in decompensated cirrhosis: characterization and role in acute-on-chronic liver failure," Hepatology, vol. 64, no. 4, pp. 1249-1264, 2016.

[55] H. Guo, J. B. Callaway, and J. P.-Y. Ting, "Inflammasomes: mechanism of action, role in disease, and therapeutics," Nature Medicine, vol. 21, no. 7, pp. 677-687, 2015.

[56] D. Lester, "Endogenous ethanol: a review," Quarterly Journal of Studies on Alcohol, vol. 22, no. 4, pp. 554-574, 1961.

[57] N. Ganne-Carrié and P. Nahon, "Hepatocellular carcinoma in the setting of alcohol-related liver disease," Journal of Hepatology, vol. 70, no. 2, pp. 284-293, 2019.

[58] L. Zhu, S. S. Baker, C. Gill et al., "Characterization of gut microbiomes in nonalcoholic steatohepatitis (NASH) patients: a connection between endogenous alcohol and NASH," Hepatology, vol. 57, no. 2, pp. 601-609, 2013.

[59] N. L. Gluchowski, M. Becuwe, T. C. Walther, and R. V. Farese Jr., "Lipid droplets and liver disease: from basic biology to clinical implications," Nature Reviews Gastroenterology \& Hepatology, vol. 14, no. 6, pp. 343-355, 2017.

[60] S. Just, S. Mondot, J. Ecker et al., "The gut microbiota drives the impact of bile acids and fat source in diet on mouse metabolism," Microbiome, vol. 6, p. 134, 2018.

[61] H. An, S. Park, D. Lee et al., "Antiobesity and lipid-lowering effects of bifidobacterium spp. in high fat diet-induced obese rats," Lipids in Health and Disease, vol. 10, no. 1, p. 116, 2011.

[62] G. Svegliati-Baroni, I. Pierantonelli, P. Torquato et al., "Lipidomic biomarkers and mechanisms of lipotoxicity in non-alcoholic fatty liver disease," Free Radical Biology and Medicine, vol. 144, pp. 293-309, 2019.

[63] L. Chrostek, L. Supronowicz, A. Panasiuk, B. Cylwik, E. Gruszewska, and R. Flisiak, "The effect of the severity of liver cirrhosis on the level of lipids and lipoproteins," Clinical and Experimental Medicine, vol. 14, no. 4, pp. 417-421, 2014.

[64] M. Raman, I. Ahmed, P. M. Gillevet et al., "Fecal microbiome and volatile organic compound metabolome in obese humans with nonalcoholic fatty liver disease," Clinical Gastroenterology and Hepatology, vol. 11, no. 7, pp. 868-875, 2013.

[65] N. Jiao, S. S. Baker, A. Chapa-Rodriguez et al., "Suppressed hepatic bile acid signalling despite elevated production of primary and secondary bile acids in NAFLD," Gut, vol. 67, no. 10, pp. 1881-1891, 2018.

[66] C. Ma, M. Han, B. Heinrich et al., "Gut microbiome-mediated bile acid metabolism regulates liver cancer via NKT cells," Science, vol. 360, no. 6391, 2018.

[67] J. Ueda, K. Chijiiwa, K. Nakano, G. Zhao, and M. Tanaka, "Lack of intestinal bile results in delayed liver regeneration of normal rat liver after hepatectomy accompanied by impaired cyclin E-associated kinase activity," Surgery, vol. 131, no. 5, pp. 564-573, 2002.

[68] J. L. García-Rodríguez, L. Barbier-Torres, S. FernándezÁlvarez et al., "SIRT1 controls liver regeneration by regulating bile acid metabolism through farnesoid $\mathrm{X}$ receptor and mammalian target of rapamycin signaling," Hepatology, vol. 59, no. 5, pp. 1972-1983, 2014.
[69] D. Cyranoski, "Why Chinese medicine is heading for clinics around the world," Nature, vol. 561, no. 7724, pp. 448-450, 2018.

[70] Y. Ma, M. Chen, Y. Guo et al., "Prevention and treatment of infectious diseases by traditional Chinese medicine: a commentary," Apmis, vol. 127, no. 5, pp. 372-384, 2019.

[71] S. Z. Wan, C. Liu, C. K. Huang, F. Y. Luo, and X. Zhu, "Ursolic acid improves intestinal damage and bacterial dysbiosis in liver fibrosis mice," Frontiers Pharmacology, vol. 10, p. 1321, 2019.

[72] S.-S. Sun, K. Wang, K. Ma, L. Bao, and H.-W. Liu, “An insoluble polysaccharide from the sclerotium of poria cocos improves hyperglycemia, hyperlipidemia and hepatic steatosis in ob/ob mice via modulation of gut microbiota," Chinese Journal of Natural Medicines, vol. 17, no. 1, pp. 3-14, 2019.

[73] J. Leng, F. Huang, Y. Hai et al., "Amelioration of non-alcoholic steatohepatitis by Qushi Huayu decoction is associated with inhibition of the intestinal mitogen-activated protein kinase pathway," Phytomedicine, vol. 66, Article ID 153135, 2020.

[74] Q. Li, M. Li, F. Li et al., "Qiang-Gan formula extract improves non-alcoholic steatohepatitis via regulating bile acid metabolism and gut microbiota in mice," Journal of Ethnopharmacology, vol. 258, Article ID 112896, 2020.

[75] L. Xu, X. Zheng, Y. Wang et al., "Berberine protects acute liver failure in mice through inhibiting inflammation and mitochondria-dependent apoptosis," European Journal of Pharmacology, vol. 819, pp. 161-168, 2018.

[76] W. Li, H. Yang, Q. Zhao, X. Wang, J. Zhang, and X. Zhao, "Polyphenol-rich loquat fruit extract prevents fructose-induced nonalcoholic fatty liver disease by modulating glycometabolism, lipometabolism, oxidative stress, inflammation, intestinal barrier, and gut microbiota in mice," Journal of Agricultural and Food Chemistry, vol. 67, no. 27, pp. 77267737, 2019.

[77] Y.-X. Chen, L.-N. Lai, H.-Y. Zhang et al., "Effect of artesunate supplementation on bacterial translocation and dysbiosis of gut microbiota in rats with liver cirrhosis," World Journal of Gastroenterology, vol. 22, no. 10, pp. 2949-2959, 2016.

[78] Y. Zhang, K. Tang, Y. Deng et al., "Effects of Shenling Baizhu powder herbal formula on intestinal microbiota in high-fat diet-induced NAFLD rats," Biomedicine \& Pharmacotherapy, vol. 102, pp. 1025-1036, 2018.

[79] N. Li, B. Wang, Y. Wu et al., "Modification effects of San Wei Gan Jiang Powder on liver and intestinal damage through reversing bile acid homeostasis," Biomedicine \& Pharmacotherapy, vol. 116, Article ID 109044, 2019.

[80] A. M. Neyrinck, U. Etxeberria, B. Taminiau et al., "Rhubarb extract prevents hepatic inflammation induced by acute alcohol intake, an effect related to the modulation of the gut microbiota," Molecular Nutrition Food Research, vol. 61, no. 1, 2017.

[81] B. Gao, R. Wang, Y. Peng, and X. Li, "Effects of a homogeneous polysaccharide from Sijunzi decoction on human intestinal microbes and short chain fatty acids in vitro," Journal of Ethnopharmacology, vol. 224, pp. 465-473, 2018.

[82] T. Li, H. Teng, F. An, Q. Huang, L. Chen, and H. Song, "The beneficial effects of purple yam (Dioscorea alata L.) resistant starch on hyperlipidemia in high-fat-fed hamsters," Food \& Function, vol. 10, no. 5, pp. 2642-2650, 2019.

[83] W.-L. Guo, Y.-Y. Pan, L. Li, T.-T. Li, B. Liu, and X.-C. Lv, "Ethanol extract of Ganoderma lucidum ameliorates lipid metabolic disorders and modulates the gut microbiota 
composition in high-fat diet fed rats," Food \& Function, vol. 9, no. 6, pp. 3419-3431, 2018.

[84] S. Wan, F. Luo, C. Huang, C. Liu, Q. Luo, and X. Zhu, "Ursolic acid reverses liver fibrosis by inhibiting interactive NOX4/ ROS and RhoA/ROCK1 signalling pathways," Aging, vol. 12, no. 11, pp. 10614-10632, 2020.

[85] S. Wang, S. Long, and W. Wu, "Application of traditional Chinese medicines as personalized therapy in human cancers," The American Journal of Chinese, Medicine, vol. 46, no. 5, pp. 953-970, 2018.

[86] Z. Guan, T. A. Garrett, and H. Goldfine, "Lipidomic Analysis of Clostridium cadaveris and Clostridium fallax," Lipids, vol. 54, no. 8, pp. 423-431, 2019.

[87] S. Huang, F. Mu, F. Li et al., "A network-based approach to explore the mechanism and bioactive compounds of erzhi pill against metabolic dysfunction-associated fatty liver disease," Journal of Diabetes Research, vol. 2020, Article ID 7867245, 15 pages, 2020.

[88] J. K. Nicholson, E. Holmes, J. Kinross et al., "Host-gut microbiota metabolic interactions," Science, vol. 336, no. 6086 , pp. 1262-1267, 2012.

[89] M. G. Rooks and W. S. Garrett, "Gut microbiota, metabolites and host immunity," Nature Reviews Immunology, vol. 16, no. 6, pp. 341-352, 2016.

[90] S.-J. Yue, W.-X. Wang, J.-G. Yu et al., "Gut microbiota modulation with traditional Chinese medicine: a system biology-driven approach," Pharmacological Research, vol. 148, Article ID 104453, 2019.

[91] H. Wang, L. Guan, J. Li, M. Lai, and X. Wen, "The effects of berberine on the gut microbiota in apc ${ }^{(\mathrm{min} /+)}$ mice fed with a high fat diet," Molecules, vol. 23, no. 9, p. 2298, 2018.

[92] Y. Liu, T. Li, A. Alim, D. Ren, Y. Zhao, and X. Yang, "Regulatory effects of stachyose on colonic and hepatic inflammation, gut microbiota dysbiosis, and peripheral CD4+ $\mathrm{T}$ cell distribution abnormality in high-fat diet-fed mice," Journal of Agricultural and Food Chemistry, vol. 67, no. 42, pp. 11665-11674, 2019.

[93] F. Wang, H. Yang, Y. Li, W Wu, and Z. Zhou, "Prevention and treatment mechanism of qingxia therapy (based on yinchenhao decoction and dachengqi decoction) on hepatocyte apoptosis in rats with acute hepatic injury induced by lipopolysaccharide/D-galactosamine," Journal of Chinese Medicinal Materials, vol. 5, pp. 848-852, 2014.

[94] H. Du, T. T. Kuang, S. Qiu et al., "Fecal medicines used in traditional medical system of China: a systematic review of their names, original species, traditional uses, and modern investigations," Chinese Medicine, vol. 14, p. 31, 2019. 